\title{
Ureterovesical Obstruction
}

National Cancer Institute

\section{Source}

National Cancer Institute. Ureterovesical Obstruction. NCI Thesaurus. Code C98901.

Blockage of the opening between the ureter and the bladder resulting in the reduction or prevention of the urine flow from the ureter to the bladder. 